\title{
GÊNERO E DIVERSIDADE SEXUAL NO ESPAÇO ESCOLAR: TEMÁTICAS QUE NECESSITAM SER ABORDADAS ${ }^{1}$
}

\author{
GENDER AND SEXUAL DIVERSITY IN THE SCHOOL AREA: THEMES \\ WHICH NEED TO BE ADDRESSED
}

Marilia Gomes de Carvalho ${ }^{2}$ Lindamir Salete Casagrande ${ }^{3}$

\begin{abstract}
Resumo:
O objetivo deste artigo é apresentar os resultados de um curso de capacitação que visou sensibilizar as/os profissionais da educação sobre a eqüidade de gênero e a diversidade sexual em uma pequena comunidade do litoral do Paraná (Matinhos). Foram realizadas diversas atividades que visavam atingir o objetivo do curso. $O$ método participativo utilizado permitiu que as/os pesquisadoras/es trocassem conhecimentos sobre os temas planejados para o curso, buscando construir concepções de gênero mais igualitárias em suas comunidades locais. Com este método foi possível a produção conjunta de conhecimentos sobre os problemas que as profissionais da educação encontram em sua prática escolar, como conseqüência de preconceitos e discriminações de gênero. Acreditase que o objetivo do curso foi alcançado e que os profissionais foram sensibilizados e poderão aplicar e multiplicar estes conhecimentos em seu cotidiano escolar.
\end{abstract}

Palavras-chave: Relações de gênero; diversidade sexual; educação; ambiente escolar

\begin{abstract}
:
The objective of this paper is to present the results of a training course aimed at raising awareness of gender equity and sexual diversity in education professionals in a small community on the coast of Paraná (Matinhos). Several activities were held aimed at achieving the objective of the course. The participatory approach used in the course enabled the researchers to exchange knowledge on the issues, seeking to build more egalitarian conceptions of gender in their local communities. With this method it was possible to joint production of knowledge about the problems that education professionals face in relation to prejudice and discrimination of gender in their practice in school. It is believed that the objective of the course was reached and that professionals were aware and may apply and multiply this knowledge in their daily routines in their schools.
\end{abstract}

Keywords: Gender relations; Sexual diversity; Education; School environment.

Agradecemos a todas as pessoas que contribuíram no desenvolvimento deste projeto, quer como professores, quer como alunos. Sem a participação de todas/os seria impossível levar este projeto adiante.

2 Doutora em Antropologia Social pela Universidade de São Paulo - USP, professora do Programa de Pós-Graduação em Tecnologia - PPGTE, da Universidade Tecnológica Federal do Paraná UTFPR, coordenadora e pesquisadora do Grupo de Estudos e Pesquisas sobre Relações de Gênero e Tecnologia - GeTec.

3 Doutoranda em Tecnologia pelo PPGTE/UTFPR, professora da UTFPR, pesquisadora do GeTec, Coordenadora Editorial dos Cadernos de Gênero e Tecnologia do GeTec/PPGTE. 


\section{INTRODUÇÃO}

Além da família, instituição responsável pela educação e cuidados com os novos membros da sociedade, a escola é a outra instituição que também se ocupa desta tarefa; portanto, família e escola são as principais responsáveis pelas masculinidades e feminilidades que estão sendo formadas em nossa sociedade. É no processo educativo, principalmente na família e na escola, que os padrões de comportamento, as regras sociais, os valores éticos e morais, os costumes, os estereótipos, são transmitidos para as crianças (CARVALHO, 1992). A transmissão da cultura ocorre também através de outros mecanismos sociais, como a mídia ou a religião, mas família e escola são instituições fundamentais no processo de socialização dos novos membros da sociedade.

Tais instituições são justamente aquelas nas quais mais se observa a relevante posição ocupada pelas mulheres. Não se pode negar o importante papel que as mulheres têm na transmissão dos padrões de sociabilidade às novas gerações, não só em função da maternidade e o conseqüente cuidado com os filhos, que Ihes é tradicionalmente delegado pela família, mas também porque na escola fundamental, especialmente nas séries iniciais, as mulheres ocupam quase que totalmente as funções de professoras, merendeiras, zeladoras, secretárias, diretoras, enfim são elas que estão à frente de todas as atividades escolares dirigidas para as crianças. As mulheres têm, pois, um papel fundamental no desenvolvimento local e uma significativa tarefa na transformação (ou não) de suas comunidades em direção a padrões mais democráticos em que os direitos humanos sejam realmente respeitados.

Faz parte destes padrões culturais as concepções de gênero que incluem desde os papéis que devem ser desempenhados por homens e mulheres, até a rigidez de estereótipos de gênero que resultam quase sempre em preconceitos e discriminações. O movimento feminista vem há décadas questionando o lugar da mulher na sociedade e as relações de poder que permeiam a construção do gênero nas sociedades de tradição patriarcal. Porém não se pode negar que há mulheres que, inadvertidamente, têm reproduzido estes padrões, pois na medida em que são figuras principais na socialização das crianças, algumas vezes elas contribuem para a formação de homens e mulheres machistas e dominadores, que aprendem a adotar atitudes preconceituosas com relação à diversidade sexual e ao gênero. É claro que as mulheres não são as únicas responsáveis pela reprodução e/ou manutenção dos padrões sócioculturais que existem há séculos e que foram por elas introjetados, porém deve-se ressaltar a possibilidade de transformá-los através da atuação educativa das mães e professoras.

Foi a partir da constatação deste papel relevante das mulheres em suas comunidades locais que foi elaborado o projeto "Gênero e diversidade sexual no ambiente escolar: a importância de repensar conceitos e preconceitos", do qual trata este artigo.

\section{O PROJETO}

O projeto referido acima visou contribuir para a formação de profissionais 
de ensino fundamental da rede pública municipal com relação aos seguintes itens:

- oportunizar o acesso a um referencial teórico que faça a discussão de conceitos como igualdade de gênero, homofobia, diversidade sexual;

- provocar reflexões críticas entre os profissionais da educação sobre a construção dicotômica de gênero em nossa sociedade e suas conseqüências quanto à discriminação e preconceitos;

- sensibilizar profissionais da educação das escolas-alvo do projeto, para a modificação de estereótipos de gênero que geram comportamentos discriminatórios;

- auxiliar os/as professores/as a utilizar criticamente o material didático em sala de aula quanto aos conteúdos de gênero que contribuem para: (a) invisibilidade histórica das mulheres na construção da sociedade brasileira, da ciência e da tecnologia, (b) reprodução dos padrões tradicionais, conservadores e discriminatórios de gênero, tais como linguagem escrita e visual;

- problematizar questões como a violência de gênero, enfatizando a violência contra as mulheres, violência doméstica e violência contra homossexuais, transexuais e travestis;

- problematizar, juntamente com profissionais da educação, a definição de profissões "masculinas" ou "femininas" e o conseqüente direcionamento e/ou enquadramento dos alunos em determinadas profissões (geralmente de conteúdos técnicos) e das alunas em profissões de conteúdos voltados às ciências humanas, às artes e às áreas do "cuidado";

- problematizar, juntamente com os profissionais da educação, comportamentos homofóbicos na sociedade em geral e na escola em particular e suas conseqüências de exclusão às pessoas que não seguem os padrões hegemônicos de gênero;

- repensar, junto aos profissionais da educação, formas de inclusão para todos que sofrem discriminação de gênero, seja por orientação sexual, seja por escolhas profissionais.

A população para a qual se dirigiu este projeto era composta por profissionais da educação da rede municipal do município de Matinhos, no Estado do Paraná, incluindo:

- dDiretores/as das escolas, supervisores/as de ensino, professoras e professores, orientador/as educacionais, psicólogas/os, inspetoras/es, zeladores/as, serventes e demais profissionais;

- pais da comunidade que têm participação ativa no cotidiano escolar, como membros da associação de pais e mestres.

Este projeto foi desenvolvido pelas pesquisadoras ${ }^{4}$ do Grupo de Estudos

4 A grande maioria das participantes (como alunas e professoras) eram mulheres e professoras, sendo assim, optou-se por utilizar neste texto o feminino sempre que nos referir às pessoas que participaram do curso. 
e Pesquisas sobre Relações de Gênero e Tecnologia- GeTec do Programa de Pós-Graduação em Tecnologia - PPGTE da Universidade Tecnológica Federal do Paraná - UTFPR e do Grupo Interdisciplinar de Estudos sobre Representações de Gênero e Diversidade Sexual - REGEDI da Universidade Federal do Paraná - Campus Litoral em parceria com a Secretaria Municipal de Educação e Cultura de Matinhos, Paraná, cidade com um dos índices de desenvolvimento humano mais baixos do Estado do Paraná e financiamento da Secretaria de Educação Continuada, Alfabetização e Diversidade SECAD/MEC.

As professoras pesquisadoras de ambos os Grupos de Pesquisa das duas universidades envolvidas ministraram as aulas seguindo a metodologia pedagógica participativa proposta pelo educador Paulo Freire, em que os conteúdos eram trazidos pelas profissionais da educação que fizeram o curso a partir de sua realidade vivida, seja na escola, com os/as alunos/as, seja em outras situações da vida. (FREIRE, 1987). A pesquisa não era objetivo central do curso, entretanto o olhar de pesquisador das professoras não deixou de captar informações que agora constituem base para a elaboração deste estudo.

O curso foi planejado e desenvolvido em quatro módulos que totalizaram 40 horas-aula. No módulo 1, que teve duração de 8 horas/aula foram abordados os conceitos que norteariam o trabalho das professoras/pesquisadoras em todo o curso. Apresentaram-se as diversas correntes teóricas do conceito de gênero, buscando a reflexão sobre a construção das masculinidades e feminilidades.

Fez-se, também, a reflexão sobre os conceitos de sexualidade, problematizando a heterossexualidade normativa. Buscou-se proporcionar às participantes a reflexão sobre a diversidade sexual e as conseqüências da exclusão dos homossexuais, transexuais e travestis do ambiente escolar e, por conseqüência, da vida em sociedade. Para e discussão destes temas buscouse a realização de atividades ${ }^{5}$ que propiciavam a participação de todas, o que de fato ocorreu.

O segundo módulo teve a duração de 16 horas-aula e abordou a temática de gênero no ambiente escolar. Neste módulo, a participação foi intensa, pois se tratava do local de trabalho da maioria que se identificava com a temática ali apresentada e com os problemas levantados pelos colegas e pelas professoras do módulo. As discussões abordaram temas tais como: representações de gênero nos livros didáticos, relações de gênero nos momentos extraclasse como antes do início das aulas, nos intervalos e na saída e gênero e diversidade escolar no currículo explícito e oculto (datas comemorativas, brincadeiras, filas, no banheiro, etc.).

O debate sobre como utilizar livros de literatura infantil para introduzir a temática da sexualidade na educação infantil se mostrou bastante frutífero. Este foi um dos momentos em que as participantes mais gostaram do curso, pois

5 Em todo o curso buscou-se a utilização de atividades que propiciassem a participação de todas, tornando o curso mais dinâmico e produtivo. Algumas atividades serão mais bem detalhadas adiante. 
além de apresentar conceitos, provocar discussões e debates, a reflexão sobre assuntos que faziam parte do cotidiano da maioria, embora muitas vezes não fossem percebidos por elas, se revelou de grande interesse. Foram propostas atividades que poderiam auxiliá-las no cotidiano escolar.

No terceiro módulo abordou-se a questão de gênero e diversidade sexual e sua relação com a ciência e a tecnologia. Após uma breve explanação sobre os conceitos de ciência a tecnologia que seriam adotados pelas professoras, a discussão foi direcionada para a escolha das profissões, buscando refletir sobre o papel da escola nesta escolha, bem como na identificação dos alunos com determinadas disciplinas. Alguns dos questionamentos que nortearam as discussões foram: será que a escola interfere nas escolhas das profissões para meninos e meninas? E no gosto e aptidão para as disciplinas escolares? Esta discussão levou algumas participantes a refletirem sobre suas práticas docentes.

Outro assunto abordado neste módulo foi o acesso, a produção e o uso de tecnologias, sob a ótica de gênero. As discussões giraram em torno do fato de que muitas vezes pensa-se que a mulher não tem capacidade ou habilidade para desenvolver nem para usar a tecnologia. Essa visão equivocada sobre a mulher pode fazer com que se incentive mais os meninos e menos as meninas para, quando adultos, seguirem carreiras na área tecnológica.

O encerramento do curso deu-se com o módulo 4, no qual foi abordado o tema gênero e mídia. Neste módulo analisou-se como a mídia contribui para a construção da imagem de homens e de mulheres. $O$ uso de fotos e ilustrações retiradas das mais variadas revistas e que reproduzem papéis estereotipados de gênero contribuiu para ilustrar este tema. Outra mídia utilizada na reflexão foi o cinema, com a projeção de trechos de filmes. A maioria das participantes já havia assistido aos filmes selecionados, porém nunca tinha refletido sobre a forma como eles representavam homens e mulheres.

Em todos os módulos, as professoras desempenharam o papel de mediadoras, explorando a experiência vivida pelas profissionais da educação, trabalhando os conteúdos programados a partir da realidade trazida pelas participantes.

As atividades foram diversificadas, partindo de diversas dinâmicas de grupo, tais como: levantamento de situações-problema, oficinas, aulas expositivas dialogadas, vivências, palestras com especialistas no tema, utilização de recursos audiovisuais, confecção de cartazes temáticos, projeção de filmes e vídeos para discussões posteriores, dentre outras.

Estas dinâmicas foram aplicadas durante as aulas de forma tal que as pessoas participantes sentiam-se à vontade para falar sobre vários assuntos: desde suas limitações na compreensão do tema gênero; as dificuldades de trabalhar com seus alunos e alunas questões relacionadas à sexualidade; situações vividas em que reproduziam inadvertidamente padrões dicotômicos de gênero, sem a devida crítica às relações de poder que se estabelecem entre homens e mulheres; o incentivo maior dado aos alunos para as disciplinas voltadas para as ciências exatas, como a Matemática por exemplo, e, por outro lado, o incentivo maior dado às alunas para o bom comportamento ou atividades que as preparam para as áreas do cuidado; as dificuldades que tinham e, 
mesmo a falta de conhecimento adequado, para lidar com situações nas quais surgiam preconceitos e discriminações com relação a questões relativas à homossexualidade, que muitas vezes culminavam em homofobia.

No decorrer das aulas, os conceitos e preconceitos de gênero foram aos poucos sendo desconstruídos e foram construídos em seu lugar pensamentos mais igualitários com relação a papéis de homens e mulheres na sociedade, abrindo a possibilidade da troca dos padrões tradicionais de homens e mulheres e provocando questionamentos sobre profissões majoritariamente masculinas ou femininas que dificultam a inserção das mulheres nas primeiras e dos homens nas segundas.

\section{BASE CONCEITUAL DO PROJETO}

Conceitos teóricos foram fundamentais para dar sustentação às idéias que nortearam este projeto desde a sua concepção até o encerramento das atividades e a sua avaliação. Não vamos trazer aqui detalhes minuciosos das discussões teóricas que acompanharam todo o processo, porém convém ressaltar alguns conceitos.

Segundo Simião, a categoria gênero pode ser entendida "como uma linguagem, uma forma de comunicação e ordenação do mundo, que orienta a conduta das pessoas em suas relações específicas, e que é, muitas vezes, base para preconceitos, discriminação e exclusão social" $(2005$, p. 13). Para Felipe e Guizzo, gênero está "relacionado fundamentalmente aos significados que são atribuídos ao ser mulher ou ao ser homem em diferentes sociedades e épocas" (2003, p. 121). Por sua vez, Young (2003) compreende gênero como uma forma particular de posicionamento social dos corpos vividos em relação uns aos outros, dentro de instituições e processos históricos específicos que tem efeitos materiais na ação e reprodução de relações de poder e privilégio entre si. Sob essa ótica, o que significa dizer que indivíduos são "generizados" é que todos nós nos encontramos passivamente agrupados de acordo com essas relações estruturais, de maneiras muito impessoais para fundar identidades.

Assim, faz-se necessário refletir sobre as relações de gênero e diversidade sexual nos múltiplos setores da sociedade. Ao analisar livros didáticos, percebe-se claramente a ocultação de uma orientação não heterossexual e uma segregação feminina nas mais diversas disciplinas. Tais fatos constituem bases para a construção das identidades e da formação dos modelos que serão seguidos pelas crianças.

Casagrande (2005) aponta como os livros didáticos de Matemática reproduzem representações de gênero estereotipadas e conservadoras que discriminam as mulheres de atividades da esfera pública, como o mundo do trabalho, ciência e tecnologia.

Louro (1997) ressalta o papel da escola na construção e manutenção das diferenças entre homens e mulheres e aponta para a necessidade de demonstrar que "não são propriamente as características sexuais, mas é a forma como essas características são representadas ou valorizadas, aquilo que se diz ou se pensa sobre elas que vai constituir, efetivamente, o que é feminino 
ou masculino em uma dada sociedade em um dado momento histórico" (LOURO, 1997, p. 21).

Outra autora a ser considerada é Wittig (1992), para quem o pensamento "hetero" apenas pode conceber uma cultura ou sociedade, no qual a heterossexualidade ordene as relações humanas, a produção de conceitos e os processos conscientes e inconscientes. Assim, é produzida uma leitura da realidade na qual os seres humanos são dados como não tocados pela história. A autora critica a psicanálise e o estruturalismo, referindo que foram encontradas no inconsciente as estruturas que tinham sido lá postas previamente; essas estruturas seriam opressoras porque, dizendo respeito a categorias como mulher, homem, sexo, relacionamentos, estão fundadas sobre a heterossexualidade, pensamento que produz a diferença entre os sexos como um dogma político e filosófico. Assim, a diferença entre os sexos afeta todos os conceitos que integram as disciplinas; porém, não existe um ser-mulher ou um ser-homem porque não há nada de ontológico na diferença. A função da diferença é a de ocultar conflitos de interesse e a dominação heterossexual e masculina enquanto tal.

Bourdieu (1999) lembra que as instituições estão há milênios inscritas na objetividade das estruturas sociais e na subjetividade das estruturas cognitivas, e pensam o feminino e o masculino com um espírito estruturado segundo esta oposição.

Para Wittig (1981), a prática repetida de nomear a diferença sexual criou a divisão natural e somos obrigados em nossos corpos e mentes, a corresponder à idéia de natureza que foi estabelecida para nós. Assim, homens e mulheres são categorias políticas e não dados naturais.

Butler (2003) ilumina esse debate, referindo que o sexo não é o que alguém tem ou é, mas constitui uma das normas que qualifica um corpo para a vida no interior da inteligibilidade cultural. O que ocorre é que os gêneros considerados inteligíveis são aqueles que instituem relações de coerência entre o sexo, o gênero, a prática sexual e o desejo, dentro da norma heterossexual, requerendo e instituindo oposições assimétricas entre o feminino e o masculino. A matriz cultural na qual a identidade de gênero se torna inteligível exige que outros tipos de identidade não possam existir, ou seja, aquelas em que o gênero não decorra do sexo, ou onde as práticas do desejo não sejam coerentes com o que se espera de um sexo vinculado a um gênero, tais como mulheres que desejam afetiva e sexualmente outras mulheres e homens que se sentem atraídos afetivamente e sexualmente por outros homens.

Dessa forma, embora muito se tenha discutido, em anos recentes, sobre a imbricação da natureza/cultura, a heterossexualidade, orientação sexual da grande maioria das pessoas nas sociedades conhecidas, foi erigida em conhecimento tácito, axioma, princípio óbvio, dado pré-adquirido a qualquer ciência. No entanto, a heterossexualidade deve ser examinada enquanto categoria cultural, no sentido de que organiza a sociedade de forma hierárquica e assimetricamente generizada.

Essas questões são contempladas por Young (2003), quando propõe três eixos básicos de estruturas de gênero: a divisão sexual do trabalho, a heterossexualidade normativa $\mathrm{e}$ as hierarquias generizadas de poder. A 
estruturação de gênero na sociedade, conforme a heterossexualidade normativa consiste nos diversos fatos ideológicos e institucionais que privilegiam à heterossexualidade, incluindo leis, regras políticas, organizações públicas e privadas; a educação formal e da mídia de massas seguem essas normas e supõem o que as pessoas fazem em suas relações com os outros. Esses fatos sociais constroem estruturas com diversas conseqüências na vida de diferentes homens e mulheres, que, com a variedade de inclinações sexuais, produzem grandes sofrimentos e limitações à liberdade. Assim, enquanto alguns procuram ajustar suas vidas, visando aceitação, outros vivem nas lacunas das relações sociais, e outros ainda se rebelam contra essa normatização.

Como diz Bobbio (2002), os preconceitos nascem nas cabeças das pessoas e devem ser combatidos, com o desenvolvimento das consciências, com a educação, e mediante a luta constante contra toda forma de discriminação. Para o autor, o juízo negativo que é dado em nossa sociedade às mulheres e à homossexualidade também é de origem histórica e varia conforme as sociedades e no tempo. Estudos apontam que essa discriminação/preconceito está presente no ambiente escolar. Profissionais da educação, por exemplo, têm expectativas diferentes para meninos e meninas com relação à produtividade, ao capricho e às aptidões (CARVALHO, 2001). Tabak (2002) aponta ainda a permanência de carreiras e profissões tidas como "naturalmente" femininas e masculinas.

É relevante, portanto, que as/os profissionais da educação estejam atentas/os para que suas atitudes dentro e fora de sala de aula não reforcem a idéia de que as meninas e os meninos podem seguir apenas determinadas carreiras e que sua orientação sexual seja motivo para exclusão social ou a prática de violência contra pessoas que não se pautam pela heteronormatividade Os estudos acima apontam que as questões de gênero vêm sendo discutidas sob os mais diversos aspectos na Academia, porém essas discussões não atingem a população como um todo, nem tampouco o ambiente escolar. Este fato ficou demonstrado na medida em que se avançava nas atividades junto às profissionais da educação e nas avaliações que elas mesmas fizeram do curso.

\section{AS ATIVIDADES}

No decorrer do curso foram propostas diversas atividades que contaram com a participação efetiva das participantes. A seguir, apresentaremos algumas destas atividades.

O que é sexualidade na concepção das participantes.

Para esta atividade solicitou-se que as participantes falassem sobre situações vividas que estivessem

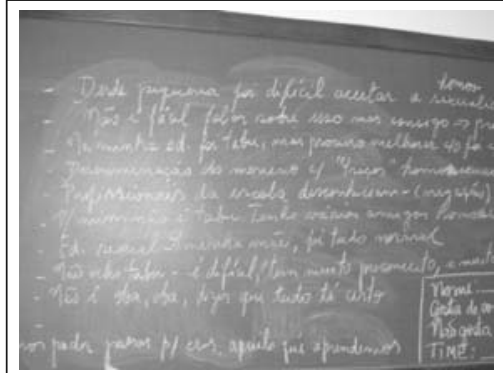

Figura 1: Falas das participantes Fonte: Foto das autoras. relacionadas à sexualidade. Surgiram afirmações como as que se seguem: 
"Desde pequena foi difícil aceitar a homossexualidade".

"Não é fácil falar sobre isso, mas eu consigo. Já fui chamada de professora depravada por falar sobre sexualidade". gente".

Na minha educação foi tabu, mas procuro melhorar como foi com a

"Para mim não é tabu, tenho vários amigos homossexuais".

"Não acho tabu, é difícil, tem muito preconceito, mas pode mudar".

"Homossexualismo não é natural".

"Não é oba, oba, dizer que está tudo certo".

Deus criou o homem e a mulher, mas não se deve tratar com preconceito".

A questão da homossexualidade esteve muito presente nas situações levantadas por elas, o que demonstra a necessidade que elas têm de falar sobre o assunto. Entretanto demonstra também que a sexualidade é, muitas vezes, confundida com homossexualidade. Esta atividade permitiu identificar, por meio de diversas falas, como é difícil para muitas falar sobre sexualidade entre elas e mais difícil ainda abordar esta temática com os alunos, evidenciando a necessidade de se realizar mais cursos semelhantes a este que é objeto deste artigo.

\section{Marcas}

O objetivo desta atividade foi refletir como as pessoas são marcadas e rotuladas por palavras e experiências ao longo da vida. Esta atividade consistiu em realizar dobraduras no papel. Para cada dobra, a participante deveria lembrar, silenciosamente, uma experiência marcante em sua vida. Depois de realizadas as dobraduras, abriam-se os papéis e fazia-se a analogia entre as marcas que ficaram nos mesmos com aquelas indeléveis que, ao longo da vida, ficaram nelas e em nós também. Esta atividade levou as participantes à reflexão sobre as marcas deixadas nelas por outras pessoas e sobre as marcas que elas deixaram nos/as outros/as. Assim, pode-se refletir sobre o papel das professoras ou professores na vida de seus alunos e alunas. Elas e eles podem deixar marcas positivas ou negativas.

Construção de uma pessoa

Foi solicitado que as participantes desenhassem um boneco com formas humanas e escrevessem neles os apelidos e nomes que se atribuem aos órgãos sexuais masculinos e femininos; apelidos pejorativos que homens e mulheres podem receber; apelidos que homossexuais masculinos e femininos podem receber. Após a construção da "pessoa" (FIGURA 2), refletiu-se sobre os apelidos e nomes constantes nos desenhos, buscando evidenciar como as pessoas podem marcar outras ao utilizarem apelidos que demonstram preconceitos e estereótipos.

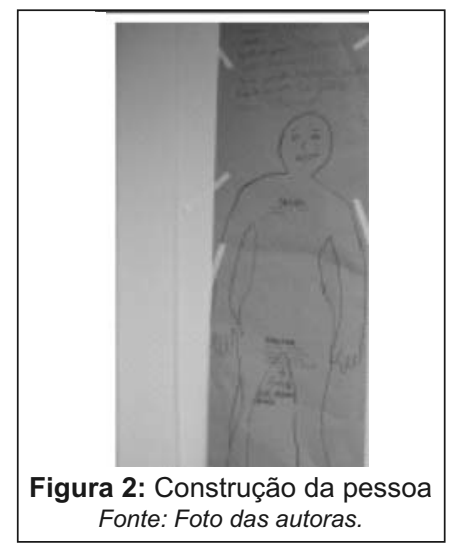


Sabe-se que entre as crianças e adolescentes brasileiros o uso de apelidos é comum. Porém deve-se refletir quais impactos os apelidos pejorativos podem ter na vida de uma pessoa, que marcas podem deixar nos outros. Esta atividade visava refletir como as palavras podem trazer marcas e devem ser consideradas como atos violentos, remetendo a atividade "marcas", acima mencionada.

\section{Uso da literatura infantil}

A literatura infantil foi utilizada em diversos momentos do curso. Às vezes para introduzir uma temática como a diversidade de famílias ${ }^{6}$, outras vezes como instrumentos para que as professoras e professores pudessem abordar a questão da sexualidade com seus alunos e alunas.

Em uma das atividades, a turma foi dividida em pequenos grupos e distribuído a eles alguns livros de literatura infantil ${ }^{7}$ para que lessem e tentassem identificar os pontos positivos, negativos, para que faixa etária era recomendado e que tipo de assunto poderia ser abordado por meio daquele livro. Posteriormente, solicitamos que os grupos falassem ao grande grupo suas impressões acerca do livro que leram. De maneira geral o desempenho das participantes foi muito bom. Elas conseguiram fazer a leitura crítica dos livros e expuseram suas opiniões com clareza. Demonstraram ter gostado da atividade pois nela estavam encontrando uma forma de abordar temas como sexualidade e reprodução humana com seus alunos.

\section{Representações de gênero nos livros didáticos}

Esta outra atividade tinha por objetivo refletir sobre como os gêneros são representados nos livros didáticos, buscando identificar se estas ilustrações trazem estereótipos de gênero. Foram selecionadas ilustrações dos livros didáticos de diversas disciplinas utilizados nas escolas nas quais as participantes trabalhavam, desta forma, o tema estava próximo a elas, e conse-

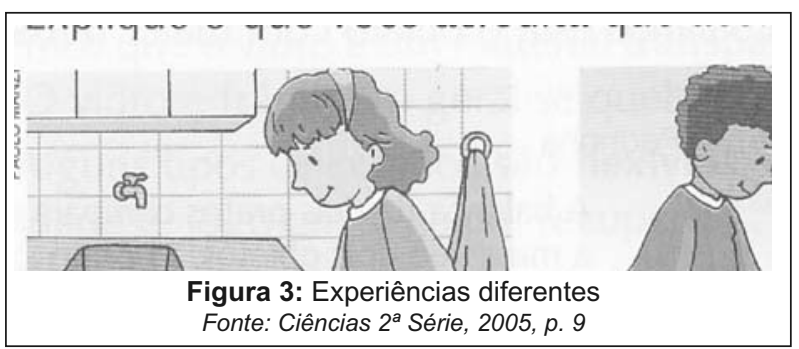

Figura 3: Experiências diferentes

Fonte: Ciências $2^{a}$ Série, 2005, p. 9 qüentemente, elas estavam motivados para a atividade.

As participantes ficavam impressionadas por perceberem que os livros que elas utilizavam estavam repletos de representações de gênero estereotipadas e, surpresos por perceberem que nunca haviam prestado atenção a isso antes. Como esta atividade foi a última do módulo 2, elas

\footnotetext{
6 Para esta atividade foi utilizado o "Livro da Família" de Todd Parr.

7 Os livros distribuídos foram "Mamãe botou um ovo" de Babette Cole; "Cabelinhos nuns lugares engraçados" de Babette Cole; "Ceci tem pipi? e "Sementinhas de fazer bebês" de Thierry Lenain, "Faca sem ponta, galinha sem pé" de Ruth Rocha.
} 
mesmas já eram capazes de analisar e perceber estes estereótipos, restando às professoras responsáveis pelo módulo fazer apenas uma complementação das análises feitas por elas. A FIGURA 3 foi uma das ilustrações analisadas. As participantes puderam perceber que a atividade que estava sendo realizada pela menina e pelo menino era a mesma, entretanto a menina estava no interior da casa e o menino no exterior. Este tipo de imagem pode reforçar a idéia de que o espaço privado é destinado às mulheres e o público aos homens.

Sim, não, talvez...

Esta atividade tinha por objetivo refletir sobre situações nas quais as manifestações de gênero estão presentes no ambiente escolar (hora do recreio, intervalo, cantina, sala de aula, dentre outras). Foram elaboradas algumas perguntas $^{8}$ e as participantes, após discutir em pequenos grupos, deveriam definir se a resposta do grupo para cada pergunta era sim, não ou talvez. Com esta atividade pôde-se debater diversas temáticas referentes ao cotidiano escolar. Algumas perguntas geraram polêmica fato que enriqueceu as discussões.

\section{Exibição de filme}

Outra forma de abordar as relações de gênero no espaço escolar foi a exibição do filme "Boneca na mochila" do diretor Reginaldo Bianco. Neste filme a professora encontra uma boneca na mochila de um menino e leva o fato à diretora. Este acontecimento ganha grandes proporções, pois chega aos ouvidos da imprensa que faz uma ampla reportagem sobre o assunto, entrevistando ouvintes por telefone. Esses ouvintes têm opiniões diversas sobre a temática. Enquanto isso, mostra-se a aflição da mãe do menino que toma um táxi para ir a escola e acompanha pelo rádio todo o "estardalhaço" que se faz sobre o assunto estabelecendo diálogo com o taxista.

Por meio deste filme pôde-se analisar como, muitas vezes por desconhecimento ou despreparo, pode-se fazer algo pequeno ganhar grandes proporções e prejudicar pessoas inocentes. Esta atividade levou as participantes a refletirem sobre a ação da professora, da diretora, da imprensa, do taxista que representa a população e da mãe diante do ocorrido. Esta reflexão pode ser transferida para o cotidiano dos mesmos no qual outras situações podem estar acontecendo e recebendo tratamento semelhante.

\section{Senhor Jacaré}

O objetivo desta atividade era iniciar as atividades de um novo dia de trabalho de forma lúdica e ao mesmo tempo demonstrar como as questões de gênero perpassam todas as situações do cotidiano, inclusive as "inocentes" brincadeiras infantis. As participantes ficaram de pé de um lado da sala e uma das professoras fazia de conta que era um jacaré. O objetivo da brincadeira era

8 Alguns exemplos de perguntas são: Meninos e meninas devem fazer educação física separados? Meninos têm caderno bagunçado? Meninas gostam mais de estudar do que meninos? 
atravessar para o outro ladro da sala sem ser pego pelo jacaré. Quem era pego virava assistente do jacaré e podia pegar os outros. Para mudar de lado as participantes deveriam fazer a seguinte pergunta: Senhor Jacaré podemos passar? E o jacaré respondia com algumas condições como por exemplo: pode passar quem está vestido de mulher; pode passar quem é bonito, dentre outras. Foi interessante notar que diante de algumas perguntas as participantes ficavam em dúvida se podiam ou não passar. As perguntas eram feitas propositadamente para provocar essas dúvidas. Após o fim da atividade, deuse início à discussão das relações de gênero no espaço escolar fora da sala de aula, e as participantes já estavam motivadas a participar das discussões.

\section{Obras de arte}

Esta atividade foi sugerida como uma forma de fechar um dia de trabalho e avaliar como os conceitos e questionamentos que estavam sendo apresentados no decorrer do curso estavam sendo absorvidos pelas participantes. Foi uma forma de avaliar, sem que elas se sentissem avaliadas. Propusemos que se unissem em grupos e realizassem uma pintura que fizesse uma síntese do que havia sido trabalhado até

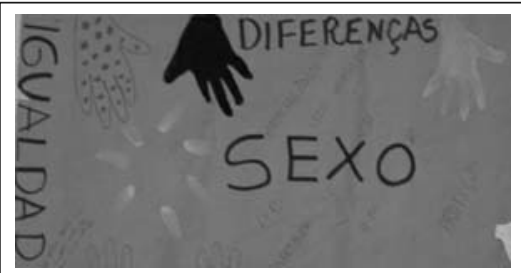

Figura 4: Mãos da diversidade Fonte: Foto das autoras. então. As produções versaram sobre diversos temas, entretanto a questão do reconhecimento e respeito à diversidade prevaleceu. Esta temática apareceu em diversas obras como, por exemplo, a FIGURA 4 na qual ela foi representada por meio das mãos.

Outro tema representado nas produções foi a necessidade de se falar sobre sexualidade com as crianças. Muitas vezes pais e professoras/es evitam esta temática por não saberem como conversar, o que falar, quando falar. A falta de conhecimento pode gerar curiosidade por parte das crianças, levando-as a buscar matar esta curiosidade muitas vezes de formas perigosas, tanto fisicamente, quanto emocionalmente. Geralmente sexualidade é confundida com relação sexual, daí a dificuldade de abordar a temática com as crianças. Neste curso especificamente, sempre que se falava sexualidade, parecia que as participantes ouviam homossexualidade. Isso chamou bastante a atenção

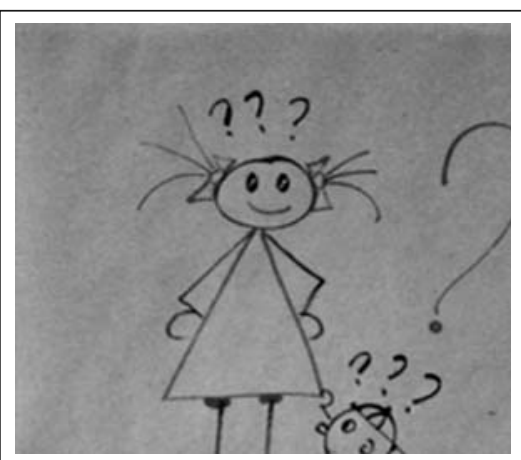

Figura 5: Curiosidade Fonte: Foto das autoras. das pesquisadoras responsáveis pelo módulo, pois representava a necessidade que as participantes tinham de falar sobre o assunto. A FIGURA 5 mostra como as participantes representaram a curiosidade infantil sobre o outro. 
Outros temas que surgiram nas "obras de arte" foi a necessidade de se manter a mente aberta para novos conceitos; a diversidade familiar; a importância de se refletir sobre os papéis que homens e mulheres assumem na sociedade, dentre outros.

\section{Representação com fantoches}

Esta foi outra atividade utilizada na avaliação. As participantes se

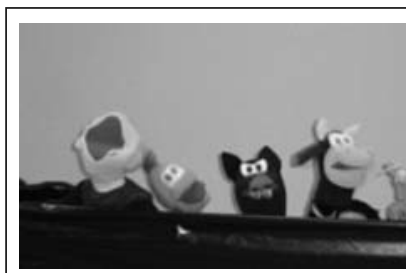

Figura 6: Representação com fantoches dividiram em pequenos grupos, escolheram fantoches e montaram histórias sobre a temática de gênero. Esta atividade foi realizada no dia em que se trabalhou a questão da diversidade nas famílias e, talvez por isso, a maioria das histórias abordava a temática das famílias "diferentes". O uso de fantoches facilitava esta representação uma vez que não existiam dois fantoches iguais. A FIGURA 6 mostra um dos grupos em ação. As participantes demonstraram alegria na realização da atividade e montaram histórias representativas sobre os estereótipos de gênero.

\section{Imagens de homem e mulheres nas revistas}

Esta atividade foi realizada no módulo que abordava as representações de gênero na mídia. Foram selecionadas imagens retiradas de revistas de circulação nacional e internacional, atuais e antigas que representavam homens e mulheres em papéis estereotipados. Por exemplo, propagandas de eletrodomésticos, sejam antigos (década de 50) sejam atuais, retratam sempre as mulheres ocupadas ou responsáveis pelo trabalho doméstico, enquanto os homens são representados como os provedores, responsáveis por comprar os aparelhos eletrodomésticos, pois são os que têm o poder econômico da família (ONO e CARVALHO, 2005). Com a exibição de tais imagens, pôde-se discutir como a mídia, em suas diversas formas de expressão, contribui para a construção estereotipada dos papéis dicotômicos e conservadores de homens e mulheres.

\section{RESULTADOS DO PROJETO}

Pode-se dizer que os resultados do projeto foram positivos, pois tudo indica que houve um repensar entre as pessoas que fizeram o curso com relação à construção do gênero e uma re-avaliação da heterossexualidade normativa.

Reproduzimos aqui algumas frases das próprias mulheres sobre suas opiniões a respeito do curso, a fim de ilustrar as repercussões que as aulas tiveram em suas vidas. Foi dada a seguinte frase para que as alunas a complementassem: "Que bom que..." 
“...a questão da diversidade ficou mais clara, às vezes você não repara nos casos do gênero abordados; uma, porque são tão sutis e outra, porque já se está acostumado(a) com a situação".

“...pude ter a oportunidade de estar assistindo este curso, podendo ampliar minha visão em relação a gênero e diversidade, sabendo que não se trata apenas de uma questão de sexualidade em si, mas também de construção de conceitos sociais".

"...eu pude participar desses temas tão importantes, para saber como tratar de vários temas diversificados".

"...tive essa oportunidade de aprender tantas coisas novas e rever meus conceitos..."

"...tive a oportunidade de participar deste curso... Adorei; gostei muito".

"...tivemos a oportunidade de tratar de assuntos relacionados aos nossos materiais de trabalho como os livros"

"...a nossa mentalidade se abriu mais"

"...pude esclarecer algumas dúvidas e saber mais a respeito dos assuntos abordados"

"...pudemos estar juntos, trocar experiências, aprendermos mais quanto aos aspectos científicos, e curiosidades"

"...abriu meu horizonte sobre sexo na escola, que é pouco falado até agora”.

"...não perdi esta oportunidade de ampliar os conhecimentos sobre todos os assuntos debatidos neste curso".

"...está existindo a possibilidade de vivenciar, aprender, trocar experiências nesse curso de capacitação".

"...tivemos esse curso para repensarmos nossas concepções e atitudes para com os outros".

“...nós temos a capacidade de aprender a cada dia as coisas que nos são passadas, ensinadas, compartilhando com as outras pessoas, assimilando as palavras".

As frases explicitadas pelas participantes do curso e reproduzidas aqui demonstram que para algumas a expressão de "abrir a cabeça" foi recorrente. Para outras, houve referência à existência de preconceitos e tabus que o curso ajudou a desconstruir. Outras ainda referiram-se à idéia da ampliação de conhecimentos e a capacidade que tiveram para aprender coisas novas. Enfim, em uma comunidade pequena (cerca de 50 mil habitantes), onde a população vive relativamente isolada de grandes centros urbanos, (muitas mulheres vieram de escolas localizadas em áreas rurais) uma experiência como esta foi marcante.

Não se pode esquecer que todas elas são profissionais da educação e poderão ser multiplicadoras das informações e conhecimentos que adquiriram. Exercem influência em suas famílias, nas escolas e na comunidade em geral. Sabe-se que é por meio da educação que se consegue modificar a sociedade e esta experiência com as mulheres que participaram deste curso possibilitouIhes uma oportunidade de conhecer e refletir sobre as questões de gênero, diversidade sexual, ciência e tecnologia a fim de que possam levar às suas comunidades alguns conhecimentos necessários para construírem um mundo 


\section{CONSIDERAÇÕES FINAIS}

As participantes se mostraram ávidas pelo conhecimento e sentiu-se a necessidade de se proporcionar outros momentos como estes para que a discussão sobre as relações de gênero, a busca pela eqüidade de gênero e o respeito à diversidade sexual dentro e fora do ambiente escolar seja ampliado e difundido a um número cada vez maior de pessoas. As participantes demonstraram bastante interesse em discutir a temática e reforçaram a necessidade da busca por cursos que auxilie as professoras e os professores a abordar assuntos tão relevantes.

Tendo em vista a importância do papel das mulheres no desenvolvimento local e sua efetiva influência nas comunidades na quais vivem, através, principalmente, de sua atuação na família e na escola; é impossível não concluir com um clamor para a necessidade de uma ampliação da experiência aqui relatada e sua replicação em outras comunidades. Desta forma, será possível alcançar uma transformação mais abrangente e multiplicadora nas desigualdades de gênero e nas relações de poder entre homens e mulheres, tão comuns em sociedades de tradição patriarcal.

\section{REFERÊNCIAS}

BOBBIO, Norberto. A natureza do preconceito. Elogio da serenidade e outros escritos morais. São Paulo: UNESP, 2002.

BOURDIEU, Pierre. A dominação masculina. Rio de Janeiro: Bertrand Brasil, 1999.

BUTLER, Judith. Problemas de gênero. feminismo e subversão da identidade. Rio de Janeiro: Civilização Brasileira, 2003.

CARVALHO, Marilia Gomes de As vicissitudes da família na sociedade moderna. Tese de Doutorado em Antropologia Social. USP, 1992.

CARVALHO, Marilia Pinto de. Mau aluno, boa aluna? Como as professoras avaliam meninos e meninas. Revista de Estudos Feministas, ano 9, $2^{\circ}$ semestre, 2001, p. 554574

CASAGRANDE, Lindamir Salete. Quem mora no livro didático?.representações de gênero nos livros de matemática na virada no milênio. Dissertação de mestrado. Programa de Pós-Graduação em Tecnologia. UTFPR. Curitiba. 2005.

EDITORA MODERNA. Projeto Pitanguá Ciências: $2^{\mathrm{a}}$ série. São Paulo: Moderna, 2005a FELIPE, Jane; GUIZZO, Bianca Salazar. Erotização dos corpos infantis na sociedade de consumo. Pro-posições, Campinas, v. 14, n. 3 (42), p. 121-130, set./dez. 2003.

FREIRE, Paulo Pedagogia do oprimido. (17ª ed.). Rio de Janeiro. Paz e Terra, 1987. LOURO, Guacira Lopes. Gênero, sexualidade e educação: Uma perspectiva pósestruturalista. Petrópolis, Vozes, 1997.

EDITORA MODERNA. Projeto pitanguá ciências: $2^{a}$ série. São Paulo: Moderna, 2005a. ONO, Maristela Mitsuko; CARVALHO, Marilia Gomes de. Isto é coisa para "mulheres": gênero e design no desenvolvimento de produtos para a sociedade. Cadernos de Gênero e Tecnologia, Curitiba, n. 2, ano 1, p. 9-29, maio/jul. 2005.

SIMIÃO, Daniel Schroeter. Gênero no mundo do trabalho: variações sobre um tema. Cadernos de Gênero e Tecnologia. vol. 5, ano 2, 2005, p. 9-20.

WITTIG, Monique. One is not Born a Woman. Feminist Issues, v.1, n.2, 1981.

WITTIG, Monique. The straight mind and other essay. Boston: Beacon, 1992

TABAK, Fanny. O laboratório de Pandora: Estudos sobre a ciência no feminino. Rio de Janeiro: Garamond, 2002.

YOUNG, Corpo vivido vs. Gênero: Reflexões sobre a estrutura social e subjetividade. 
Labrys, estudos feministas, n.3, jan./jul. 2003.

Livros de literatura infantil

COLE, Babette. Cabelinhos nuns lugares engraçados. São Paulo: Ática, 1999.

COLE, Babette. Mamãe botou um ovo. São Paulo: Ática, 1993.

LENAIN, Thierry. Ceci tem pipi? São Paulo: Companhia das Letrinhas, 2004.

LENAIN, Thierry. Sementinhas de fazer bebês. São Paulo: Larousse do Brasil, 2003.

PARR, Todd. O livro da família. São Paulo: Panda Books, 2004.

ROCHA, Ruth. Faca sem ponta, galinha sem pé. São Paulo: Ática, 1998.

Filme

Boneca na mochila, 1997 (SP, Brasil). Diretor: Reginaldo Bianco. Produtora: ECOS 